\title{
The life and death construct in heart transplant patients
}

European Journal of Cardiovascular Nursing 2019, Vol. 18(I) 48-56

(C) The European Society of Cardiology 2018 Article reuse guidelines:

sagepub.com/journals-permissions DOI: $10.1177 / 14745|5| 18785088$ journals.sagepub.com/home/cnu

\section{(S)AGE}

\author{
Ana M Palmar-Santos', Azucena Pedraz-Marcos', \\ Juan Zarco-Colón ${ }^{2}$, Milagros Ramasco-Gutiérrez ${ }^{3}$, \\ Eva García-Perea ${ }^{4}$ and Monserrat Pulido-Fuentes ${ }^{5}$
}

\begin{abstract}
Background: The technological advances of medicine, and specifically the techniques of organ transplants, have allowed crossing the border of life and death. This is especially relevant in the case of heart transplant, since its symbolism requires a redefinition not only of these traditional concepts, but also of the body or of one's own identity.

Aims: To explore the experiences of patients after receiving a heart from a donor.

Methods: A phenomenological qualitative approach, through Merleau Ponty and Levinas perspectives, was conducted to capture the subjective experiences of heart transplant patients. We conducted 22 in-depth interviews: 12 with heart transplant patients from two hospitals in Madrid (Spain), and 10 with relatives who lived with them.

Results: The line between life and death is erased for heart transplant patients. Three main themes arose from the analysis: towards death, the frontier between life and death, and towards life. The need to redefine the concepts of life and death is structured around issues such as the thought of facing one's own death and the concept of gift and resurrection.

Conclusion: Organ transplant techniques open the door to a new definition of death, of the identity of the body and its parts and the limits of life. Considering the cultural, legal, psychological, social and symbolic elements involved in the heart transplant process, a qualitative approach provides new avenues of understanding the clinical process from the patients' perspective.
\end{abstract}

\section{Keywords}

Heart transplant, in-depth interviews, lived body, phenomenology, surgical enhancement

Date received: I4 February 20I8; accepted: 4 June 2018

\section{Introduction}

The construction of life and death in a heart transplant patient requires a redefinition. The life and death boundaries and limits are overstepped. This is a process which has become more complex since the knowledge and application of new technologies in the realm of medicine. The modern invasion of the body, triggered in part by technological advances, has brought to the forefront the need to redefine the body in the light of the natural/artificial dichotomy. ${ }^{1,2}$ Medicine wields certain power over bodies and bodily parts, something that is reinforced in a mechanism of life extension. Transplant recipients appear to perceive bodily organs as a source of life, but not as life itself. ${ }^{3}$
'Department of Surgery, Universidad Autónoma de Madrid, Qualitative Health Research Group (GIQS-UAM), Spain

2Department of Sociology, Universidad Autónoma de Madrid,

Qualitative Health Research Group (GIQS-UAM), Spain

${ }^{3}$ Department of Health Promotion, Regional Health Service of Madrid,

Qualitative Health Research Group (GIQS-UAM), Spain

${ }^{4}$ Department of Surgery, Universidad Autónoma de Madrid, Spain

${ }^{5}$ Faculty of Nursing, University of Castilla-La Mancha, Talavera de la

Reina, Spain

Corresponding author:

Ana M Palmar Santos, Universidad Autónoma de Madrid, Facultad de Medicina. Departamento de Cirugía, Arzobispo Morcillo, 228029 Madrid, Spain.

Email: ana.palmar@uam.es 


\section{Eros versus Thanatos: the battle within the heart transplant recipient}

Of all the external and internal adjustments that a heart transplant recipient must make, we are interested in the concepts of the constructs of life and death, motivated by the difficulty of arriving at a definition of these two concepts. Although the definition of legal death is clear in the clinical context, there is a moral and social controversy, especially in the case of brain stem death, where the families understand the difference between life and death, but they still see a functional body. ${ }^{4}$

When a patient is legally dead, organs are withdrawn from the corpse and implanted in living patients who, from that point on, will live with another person's organs. It is similar to the story of Frankenstein, in which an individual made of pieces, fragments of others, a composite of corpse fragments, is made to then acquire his own awareness and his own life. ${ }^{5,6}$ The body of the transplant patient is doomed to fight for its own physical as well as symbolic space. The weirdness felt in relation to the implanted organ is a general occurrence in the post-transplant stage, and which is limited by the patient's self-perception. This feeling of foreignness ${ }^{2}$ is linked to the effort to internalize what is foreign, combining into one the transplanted organ (Eros) and the separating force (Thanatos). Attempts to neutralize this force will be made with immunosuppressant drugs, as well as with the patient's own drive to accept the organ. ${ }^{7}$

The techniques used in transplants are beginning to break through the limits set by nature and offer a possible solution for certain terminal illnesses. Of all the medical interventions, heart transplants are, without doubt, the ones that imply the greatest contrasts and trigger the greatest emotional strain and conflict of values. ${ }^{8}$ Mixed with the deep pain and frustration of death appears a deep happiness and joy of life. ${ }^{9}$

The anonymity of the key players in the process (donor and recipient), in our context, seeks to reinforce the idea that the donor is dead. He has disappeared, and the relatives, after mourning his passing for a certain time, need to accept the total and definitive absence. However, research suggests that relatives think that, in some way, the donor will still continue to exist in a new body, giving the organs a transcendental weight. ${ }^{4}$ This implies that, despite death, a loved one still lives on in other people. ${ }^{10}$

\section{Body and metaphor: heart and metaphor}

Bodies and metaphors are two powerful basic resources to give meaning to life. Heart transplants create significant dilemmas in this area. The implanted organ is endowed with a wealth of symbolic reference, linked to the concept of life and death. The heart, to an extent that depends on each individual culture, outweighs other organs in terms of the amount of symbolic and metaphorical connotations it holds. ${ }^{11}$ In many cases, the heart is viewed by the patient from a metonymic standpoint. This licence is justified by the role played by the heart in the body, a function that is regarded as predominant in many different cultures. Examples of the heart as a repository of the soul are abundant throughout history. For example, the hearts of Richard the Lionheart, Braveheart, Shelley, Lord Byron, Voltaire and Chopin, among others, were buried separately from the rest of their bodies, with the purpose of keeping their bodies apart from what contained their very essence. ${ }^{12,13}$

To date, research has not explored whether and how the concepts of life and death are experienced in heart transplant patients. With this study we intend to approach the phenomenon of heart transplants from an interdisciplinary perspective, to provide an understanding of the perception of life and death beyond the actual evidence and clinical processes which are associated to them. This understanding could contribute to health professionals helping patients in coping with their process and their follow-up care.

\section{Aim}

To explore life and death constructs in heart transplant patients.

\section{Methods}

A qualitative phenomenological approach was designed to capture the subjective experiences of participants who have gone through a heart transplant. ${ }^{14}$ Phenomenology focuses on exploring how human beings make sense of experience and transform it into consciousness, both individually and as shared meaning. In this research the contemporary approaches to phenomenology of Merleau Ponty and Levinas have been explored to offer the concept of a body linked to its interaction with the world and the presence of the otherness. ${ }^{15,16}$

This theoretical paradigm stems from the premise that people attribute meaning and significance to phenomena in relation to their previous experiences. ${ }^{17}$ In this study, we analyse individuals' experiences from their own perspective and from the perception that their relatives have of the process.

\section{Sample and recruitment}

Twenty-two participants from two main transplant hospitals in Madrid (Spain) were purposively recruited. Two transplant nurses, not affiliated to the study, approached, after their single experience, heart transplant recipients who met the inclusion criteria: age $\geqslant 18,15$ days to two years post-transplant (to avoid the loss of memories about 
Table I. Demographic, interview and recruitment details.

\begin{tabular}{|c|c|c|c|c|c|c|c|}
\hline $\begin{array}{l}\text { Patient } \\
\text { interviews }\end{array}$ & Sex & Age & Habitat & $\begin{array}{l}\text { Post-transplant } \\
\text { time }\end{array}$ & $\begin{array}{l}\text { Donor's } \\
\text { sex }\end{array}$ & $\begin{array}{l}\text { Family } \\
\text { interviews }\end{array}$ & $\begin{array}{l}\text { Family } \\
\text { typology }\end{array}$ \\
\hline EI & Male & 65 & Rural & Three months & Female & $\mathrm{FI}$ & Daughter \\
\hline E2 & Male & 64 & Urban & One year & Female & F2 & Wife \\
\hline E3 & Male & 33 & Urban & Four months & Male & F3 & Wife \\
\hline E4 & Male & 27 & Rural & 1.5 years & Male & F4 & Sister \\
\hline E5 & Male & 50 & Urban & 10 years & Male & F5 & Wife \\
\hline E6 & Male & 70 & Urban & 17 years & Male & - & - \\
\hline E7 & Female & 44 & Rural & 1.5 years & Male & F6 & Sister \\
\hline E8 & Female & 36 & Urban & II months & Male & F7 & Husband \\
\hline E9 & Female & 62 & Urban & One year & Male & F8 & Daughter \\
\hline EIO & Female & 37 & Urban & 10 years & Male & - & - \\
\hline EII & Female & 44 & Rural & Three years & Male & F9 & Husband \\
\hline E 12 & Female & 60 & Urban & Four years & Female & - & - \\
\hline- & - & - & - & - & - & FIO & Mother \\
\hline
\end{tabular}

the waiting period, the threat of rejection and the surgery); Spanish-speaking and medically stable (to avoid any focus on the clinical aspects). ${ }^{18}$ After the first theoretical sampling, it was decided by the researchers to include the donor's sex as a defining criterion. ${ }^{19}$ In total, 12 patients and 10 relatives were recruited (Table 1). None of the selected participants refused to collaborate or dropped out of the study.

\section{Data collection}

Data were collected through in-depth interviews, individually with each of the participants, and mostly in the privacy of their own home. The interviews were open-ended, conducted by only one interviewer using an interview guide (Table 2), lasting approximately 60 to 90 minutes, and audio recorded.

\section{Ethics and rigour}

This study was approved by one of the participating hospitals through the Clinical Research Ethics Committee (HPH-06/211). All the participants read the information sheet about the study, were able to address their concerns, and signed the consent form, which ensured their participation as volunteers, their anonymity and the confidentiality of the information. Names were substituted with an identification code. Each participant was identified by their condition of being either transplant patient or relative, and by sex or age. For example, 'Male, 27-year-old transplant patient' or 'Daughter of 65-year-old transplant patient'.

The investigation conformed to the principles outlined in the Declaration of Helsinki and Lincoln and Guba's quality criteria were adopted to assess the quality of qualitative health research ${ }^{20,21}$ (Table 3).

\section{Data analysis}

The interviews were transcribed and analysed following the discourse analysis method based on the scheme proposed by Colaizzi, conducting an upfront reading of the data, followed by a second reading to underscore words, phrases or paragraphs which held special weight in the context of the subject under study. Later, all segments were classified by meaning-based groups or subjects. ${ }^{22}$ Finally, we identified themes and sub-themes, which were interconnected, through a meaning-based network that would explain what participants experienced in relation to the proposed subject. ${ }^{23}$ Triangulation techniques were used to analyse data: all the authors participated in the review of the transcriptions and categorization scheme.

\section{Results}

The inductive analysis highlighted three main themes: towards death, the frontier between life and death, and towards life. These themes and subthemes can be seen in Table 4.

\section{Towards death}

The waiting list. The path towards death is characterized initially by the physical decline of the person; a progressive deterioration in the patient's clinical condition and general health to an extreme point, perceived very intensely by both patients and relatives. The decline perceived by relatives as the patient waiting for the transplant is an experience that they suffer with great intensity. There is a sense of relief when patients are included on a transplant waiting list; nonetheless the degree of deterioration due to the disease at this point tends to be very serious. ( $a, b$ in Table 4.) 
Table 2. Interview script.

\begin{tabular}{|c|c|c|}
\hline Goals & Subject areas & Questions \\
\hline \multirow[t]{3}{*}{$\begin{array}{l}\text { To explore life } \\
\text { and death in heart } \\
\text { transplant patients }\end{array}$} & $\begin{array}{l}\text { The moment before the } \\
\text { transplant } \\
\text { - History of the disease } \\
\text { - Diagnosis of the disease and } \\
\text { going onto the waiting list }\end{array}$ & $\begin{array}{l}\text { What was the moment they told you that they had to do a transplant } \\
\text { like? What were your thoughts about that? Did you talk to someone } \\
\text { about it? And what happened during the time you were on the waiting } \\
\text { list? Did you ever think about the possible donor? What do you } \\
\text { remember most about that stage? }\end{array}$ \\
\hline & $\begin{array}{l}\text { The operation } \\
\text { - The surgery } \\
\text { - Leaving hospital and going } \\
\text { home } \\
\text { - The donor } \\
\text { - The rejection }\end{array}$ & $\begin{array}{l}\text { How did the process go? At what point did they tell you that they } \\
\text { had a heart for you? How did you feel? What did you think about the } \\
\text { operation? What was the first thing you remember after the operation? } \\
\text { Do you remember what you told your family member after the } \\
\text { operation? As regards the rejection, what do you think it is due to? What } \\
\text { are your thoughts when you think about that? }\end{array}$ \\
\hline & $\begin{array}{l}\text { The moments after surgery. } \\
\text { - The relationship with family } \\
\text { and friends } \\
\text { - The reconstruction of the } \\
\text { subject with their disease } \\
\text { - The future }\end{array}$ & $\begin{array}{l}\text { The operation and the following days: how did he feel? Who did you talk } \\
\text { to about the transplant? What was worrying you? Did you feel different } \\
\text { at any point? What do the people who are close to you tell you? } \\
\text { The return home: how did he feel? What sort of things could you do? } \\
\text { What did you want to do but couldn't? Were there any significant } \\
\text { changes you would like to point out, as compared with before getting the } \\
\text { transplant? What do you think about having to follow medication for the } \\
\text { rest of your life? What do you think about the future? }\end{array}$ \\
\hline
\end{tabular}

Table 3. Quality criteria (Lincoln and $\mathrm{Guba}^{20}$ ).

Credibility A question guide with relevant and appropriate questions that encourage in-depth responses was designed. The investigators used triangulation technics to ensure a deep description of data. Peer debriefing was implemented in the analytical process, through two independent reviewers.

Dependability A phenomenological approach was conducted based on reflective inquiry and description of the 'lived experience' of participants in a particular context. Therefore, data were recorded and transcribed and findings were described by a set of themes.

Transferability In order to make the findings relevant to other settings, a description of the study setting and participant characteristics in detail was provided

Confirmability The main researcher worked for a long time in a cardiology section, so she had to go through a selfawareness process and analyse her own fundamental premises, fruit of her own development process and the context in which research took place

Fear. These patients face up to the dualism of fear and courage during this process. Fear is overcome either by social support or religious belief and is related to the disease, the surgery and the possibility of not surviving until the organ is available. ${ }^{12}$ (c)

\section{The frontier between life and death}

Patients at various stages of the transplant process find themselves at the frontier between life and death. In most patients, this is a physiological sense of reality. But at other times, patients create within themselves a symbolic structure of both concepts. Just as in the case of Prometheus, transplant patients find themselves trapped between life and death. They take a step towards death every day, as they lose their organ. The donor becomes a living dead man and the organ transplant patient becomes a dead living man. ${ }^{2}$ Rebirth, the return to life with a dead organ, must be understood from that transcendental dimension which accepts that what dies in the donor is reborn in a different form in the recipient.

The relation between donor and recipient suggests issues of lineage and kinship. In Western culture, the deepest root in terms of hereditary principles is the idea of parents' capacity to influence the destiny of their offspring. The blood of one's relatives can be considered the image of a biological inheritance, and the relatives can be regarded as a social link that can be seen through a mirror of the facts of natural kinship. As McCormack states in her study of Alejandro González Iñárritu's film, 21 grams, 'The notion of the family structures this bond because flesh itself is emotionally sticky as a metaphor and signifier for love, everlasting ties and the site of selfhood'. ${ }^{24}$

Transfer of personality attributes. Currently, despite scientific findings that have dispelled mythical traditions about certain traits being transferred from one being to another (unrelated by blood), through a blood or organ donation, it 
Table 4. Main results.

\section{Towards death}

The waiting list

Fear

The frontier between I

Transfer of personality attributes

Kinship

Feeling/not

feeling

\section{Towards life}

A new life begins (or 'The rebirth')

Overwhelmed by feelings

The gift (a) 'I just could not look at him, lying there prostrate, without being able to move, and I wanted to see him do something. I do know he has made an effort - huge efforts - he has even done the impossible' (daughter of 65-year-old male transplant patient).

(b) 'Waiting, having to wait was the hardest, because you see that little by little you really are dying, little by little, you see it, that you are not one bit afraid...and then another day you're doing worse...' (27-year-old male transplant patient).

(c) 'What if it hadn't arrived? That is what keeps turning around in my head. In other words, I really felt fear...I was doing very, very badly, and I was afraid. Of course, at night I couldn't even breathe properly, and I couldn't cope with much, and I kept everything to myself. I didn't tell anyone because I didn't want to upset them more than they were already' (27-year-old male transplant patient).

(d) 'Well, look, I have a good strong man's heart, since I didn't refuse it. I think that, as it's a man's heart, that must be the reason why I haven't rejected it. It's strong. It's a strong heart' (36-year-old female transplant patient).

(e) 'This donor is part of our family and is one of us, he forms part of us, and I don't care what happened to him or how it happened, or anything else. He is a good person who has saved my sister's life. And, yes, yes, of course, how could it be otherwise? How can you avoid feeling affection for him? There is no other alternative, no, no' (44-year-old sister of a female transplant patient).

(f) 'As I have somebody else's heart, blood transfusions are also from other people, aren't they? Well, I get on fine with all of us that are inside me' (70- year-old male transplant patient).

(g) 'Yes, because before, with my huge heart disease I might be lying around with a book, and the book would go up and down with each heartbeat. When I put my arm over my heart, it would go up and down. Of course! Now, afterwards, I don't notice it, and at first I noticed something strange as if [laughter]....as if I didn't have a heart, you see. But if I... if I remember the donor, then I say, "yes, it's his". But that's fine' (36-year-old female transplant patient).

(h) 'I even came to the point of thinking that I was dead but I was alive...It looked as if they were going to bury me. I said, “leave me alone! I'm alive!” (65-year-old male transplant patient).

(i) 'It was a very beautiful experience because they called me at 12:30 [crying]... on my birthday...l've been born twice' (65-year-old male transplant patient).

(j) 'I remember that once I was taking a stroll after they let me out of the hospital. I went to climb a step and I couldn't, my brain wouldn't give the order to my body. I was going to do this, and I was in stitches because I said to myself, "I can't! My leg simply will not move", and I had to go like this [she makes the movement with her leg], yes, yes. Things like that [laughter]' (36-year-old female transplant patient).

(k) 'I was crying, I cried my eyes out those days... it was a very strong emotion, from seeing yourself dead to seeing yourself well' (64-year-old male transplant patient).

(I) 'I remember that I went straight into the operating room and told the surgeons "it's time to get working and get this thing to work properly", and they all started laughing and telling me I obviously didn't need to be encouraged. Of course, not! Are we here just to piddle about? No, come on, now you get the scalpel, you open me up, you do what you have to do, and that's it. We're out of here after that' (27-year-old transplant patient).

(m) 'And, of course, we will all be donors if someday something should happen to us. They should use absolutely everything they can. But from that point to thinking that if I lose my son, no matter how many lives his death saves...I still don't have my son. The fact is, I now have my brother, but those people don't have their son' (sister of 27-year-old male transplant patient).

(n) 'But I said to them, "Well, if it's any comfort to the parents of the poor donor to know that my husband was the father of a baby we were expecting" ... if with that...they might feel, I don't know, it's not that they are going to be grandparents exactly, but something like that...lt's not that they have a grandchild themselves but, well...to think that the heart that gets excited when he hugs someone... is theirs...' (wife of 50-year-old male transplant patient).

(o) 'I feel gratitude towards absolutely everyone. First, towards the donor, his family, for making a decision at a moment like that, which must have been so hard for them. As much as you try to be, you know, objective at moments like that, I believe you can't be objective, but for a decision, whether the donor's, the family's, or whoever, to give such a lot of happiness to other people is amazing. It is, you know, in other words... a lot things happen in the world, but some good things really do happen as well; the doctors, the nurses, the support staff, all the staff, it's as you say, they are wonderful' (sister of 44-year-old female transplant patient). 
has been observed that these mythical ideas related to symbolic and vital characteristics in the collective mindset are still very much in force, following the Western historical and cultural tradition, as stated in the introduction.

This transfer of personality attributes between donor and recipient also comes into play in the case of organ transplants. In general, recipients tend to want organs from donors of their own sex. However, some women prefer to receive a man's heart, to which they attribute resistance and strength. This type of logic suggests the important influence of stereotypes linked to gender in heart transplants. (d)

The image of the donor is built on the basis of the information available about him or her. If the donor's age is more than that of the recipient's, the patients project images of a stranger who seems familiar, something like a 'protector', or the idea of a 'father figure'. Patients project positive aspects of their own situation to transfer them over to the donor. According to Winnicott's theory, the organ becomes a transitional object in this process. This use of the organ as a transitional object becomes a strategy of positive assimilation through which imaginary attributes are given to the donor; attributes which border symbolically on a fatherly description. ${ }^{25,26}$

Kinship. The concept of kinship appears in the recipient's discourse on the donor and his family, and this is also extended to the recipient's family, who share that sense of kinship. (e)

Recipients who knew that they had organs from the same donor suggested a certain level of kinship among each other. They felt a certain degree of brotherhood. ${ }^{12}$ (f)

Feeling/not feeling. The physical perception is conflictive and recipients convey a strange sensation, since they 'feel' the organ itself, something that might be triggered by clinical issues to do with the sick organ. Patients with damaged organs frequently suffer palpitations, a feeling of being in shock due to the exertion, et cetera. By contrast, with the transplanted organ, they do not feel that. It is like 'not having a heart'. Feeling/not feeling one's body becomes the first real and perceptive impact in a new phase of living with the new organ. The new organ must be 'thought about' because it is not felt. Introjection, acceptance, goes from the outside in, as the patients themselves explain about their transitional objects. $(\mathrm{g})$

The perception of imminent death at the pre-transplant stage determines the recovery from surgery and can be a truly distressing obsession. (h)

\section{Towards life}

A new life begins. For most patients, after the transplant a new road towards creating a new life begins. The idea of a rebirth takes shape, primarily due to the return to life that comes after an organ donation.

For a long time, the death of a person was linked to heart failure. It is therefore quite logical to associate the temporary removal of the heart with the state of being dead. Similarly, the physical acceptance of the organ is perceived by patients as a new birth; the date of a truly new birthday. (i, j)

Overwhelmed by feelings. The feeling of relief - of having defeated death - appears, mixed with feelings of vitality, euphoria and emotion. Occasionally, the moment of surgery is accompanied by great optimism, which can somewhat eclipse the understandable uncertainty and fear of the situation. Right after surgery, patients will very often be immediately invaded by the memory of wellbeing, at having overcome an extreme situation and waking up with a feeling of a 'fresh chance'. $(k, 1)$

The emotion lingers on much longer after that critical event itself, when reminiscing about the moment when patients are informed about a viable donor; the surgery and the experience itself, and the intensity of these moments in the past are relived again.

The gift: acceptance, gratitude and return. The organ donated has been described as a gift in the literature. ${ }^{27}$ There are societies where gifts have been given spontaneously and selflessly between people or between social groups. In this way, the person who gives, the person who receives and the one who returns what is given are all linked by the spirit inherent in the persons and the gifts. $^{28}$

A heart transplant therefore becomes a natural gift that 'is given' but it also implies certain sacrifices, a certain suffering, a certain 'payment to the gods'. As Margrit Shidrick says, a double relationship is created between donor and recipient. ${ }^{29}$ It is a relationship of solidarity, which implies that the recipient who accepts the gift becomes indebted to the donor. The recipient therefore becomes the debtor, at least until they have reciprocated what has been given to them. In this instance, the return of the gift is not possible, but this feeling of indebtedness is ongoing in recipients and their families. This need to 'return' arises from good feelings towards the donor and his family, to the point of being aware of having to 'repay', if the opportunity emerges, even being willing to become the donor. $(\mathrm{m})$

This repayment can also surface through a feeling of deservingness on the part of the recipient: taking care of oneself to be worthy of being on the waiting list; taking care of oneself to the point of obsession to preserve the hope of living again, adhering strictly to the treatment, going to regular check-ups, abiding by parallel structures through the rules of 'adequate treatment'. All this can be a way of 'deserving the organ' and can be 
regarded as a type of symbolic repayment, the gift to the donor in the form of a long life caring for the donated organ. ${ }^{29}$

The process of donating and receiving an organ is intrinsically linked to the necessity of making that organ something material, converting it into a 'thing' that can be removed, transported, inserted and made to function. It is vital to determine what is owned and what can be exchanged. This is why the organ itself, the heart, should be identified as an object of exchange. It should acquire a value in terms of use that would enable such an exchange. The transformation of part of a human being into an 'object' which can be given and received is related to a process of disassociation that makes it possible to distance oneself from the organ, to be used as an object for use and exchange; as an item of consumption, a gift. (n)

The gratitude that transplant patients feel for the donation is another factor in seeing it as a gift. They feel gratitude to the donor, the family, and the medical and non-medical staff that have made it possible. (o)

\section{Discussion}

The line between life and death in heart transplant patients is erased and it becomes complicated, at some point, to understand one as the extreme opposite of the other. Patients therefore embrace a game between being alive/not alive, dead/not dead, which forces them to search for answers to understand these concepts as complementary; as two coexisting elements of the same reality. ${ }^{13}$

One of the signs of modern life is 'the acknowledgment that science and technology are a double-edged sword, creating new boundaries of risk and danger while offering beneficial possibilities to humanity'.$^{30}$ With the changes in the conditions that define the beginning and the end of life for the human body, new possibilities emerge in the field of some terminal illnesses. Even more meaningful is that these advances imply that the relationship between the human body and an individual's identity has to be redefined, approached from a contemporary phenomenological perspective. ${ }^{31}$ The internalization of the transplanted organ is a slow, step-by-step process. Nevertheless, it can be understood as a journey the patient embarks on through a new life experience where he finds himself reconstructing his identity. ${ }^{32,33}$

This process begins with a situation of acute heart failure in which feelings of fear, loneliness, anxiety, vulnerability, discomfort or uncertainty shape patients' fragility. These feelings have been found in our study and in the literature, not only in the patients but also in the relatives. ${ }^{34,35}$

After the surgery our transplant patients expressed gratitude towards the donor, the relatives and the health professionals. ${ }^{36}$ Nevertheless, the highly complex nature of gratitude is revealed through these patients' ongoing struggle between positive and negative consequences of the transplantation, like joy, shame or guilt. ${ }^{37}$ This has been explored in other studies where the gift-of-life rhetoric has been analysed as a limitation, and the donor's anonymity complicates the reciprocity of the gift. ${ }^{38}$ Besides, these feelings of gratitude are mixed, in our study, with others that also describe the fear, uncertainty and anxiety related to being the recipient of another person's heart. ${ }^{31}$

The image of Prometheus is the metaphor of the transplant patient's journey, questioning not only life but also death itself: ${ }^{39}$ living/surviving with the heart of another person after enduring the extreme deterioration of one's own organ; living/coexisting with the gift of an organ from a person who had to die and a family who had to give, ${ }^{40}$ and also living/dying with a new birthday, a new perception of time, with a new heart.

\section{Limitations}

The strength of a qualitative inquiry, that is, the purposiveness of the sample, was also a limitation. In this study most of the patients were recruited from one public hospital as there is a national protocol for organ transplantation that homogenized the sample.

The aim of qualitative research is not the generalization but the transferability of knowledge from one situation to another. Therefore, the findings in this study can be transferred to similar contexts where patients have experienced a heart transplant.

\section{Conclusion}

The phenomenon of heart transplantation requires a multifaceted approach which would embrace the different facets involved in the process - not just clinical aspects but also the sociocultural domain - where recipients, donors' family members, healthcare professionals, researchers and the population at large all build up their own sense of this phenomenon.

As an implication of this practice, nurses need to adopt a holistic approach to comprehend the complexity of the process our patients go through, building up a new identity after the surgery, providing guidance, information, help and support to donors and recipients. Furthermore, the particular details of patients' individual stories of illness could enable us to help them adopt healthy life styles and adhere to therapy. In addition, the inclusion of patients' stories in organ donation campaigns should focus not only on the growth of donors, but also on the understanding of becoming a transplant recipient. This could assist health professionals in understanding and predicting the expectations and stresses that accompany the decisions of donors. 


\section{Implications for practice}

- Nurses need to adopt a holistic approach to comprehend the complexity of the process our patients go through, building up a new identity after the surgery, providing guidance, information, help and support to donors and recipients.

- Furthermore, the particular details of patients' individual stories of illness could enable us to help them adopt healthy life styles and adhere to therapy.

- In addition, the inclusion of patients' stories in organ donation campaigns should focus not only on the growth of donors, but also on the understanding of becoming a transplant recipient. This could assist health professionals in understanding and predicting the expectations and stresses that accompany the decisions of donors.

\section{Declaration of conflicting interests}

The authors declare that there is no conflict of interest.

\section{Funding}

This research received no specific grant from any funding agency in the public, commercial, or not-for-profit sectors.

\section{References}

1. Vannini F and Waskul D. Body/embodiment: Symbolic interaction and the sociology of the body. New York: Routledge, 2016.

2. Nancy JL. Corpus. New York: Fordham University Press, 2008.

3. Shildrick M. Staying alive: Affect, identity and anxiety in organ transplantation. Body Soc 2015; 21: 20-41.

4. Haddow G. The phenomenology of death, embodiment and organ transplantation. Sociol Health Illn 2005; 27: 92-113.

5. Wohlmann A and Steinberg R. Rewinding Frankenstein and the body-machine: Organ transplantation in the dystopian young adult fiction series Unwind. Med Humanit 2016; 42: e26-e30.

6. O'Neill RD. 'Frankenstein to futurism': Representations of organ donation and transplantation in popular culture. Transplant Rev 2006; 20: 222-230.

7. Muslin HL. The emotional response to the kidney transplant: The process of internalization. Can Psychiatr Assoc J 1972; 17: 3-8.

8. Almgren M, Lennerling A, Lundmark M, et al. The meaning of being in uncertainty after heart transplantation - an unrevealed source to distress. Eur J Cardiovasc Nurs 2016; 16: 167-174.

9. Mauthner OE, De Luca E, Poole JM, et al. Heart transplants: Identity disruption, bodily integrity and interconnectedness. Health (London) 2015; 19: 578-594.
10. Shildrick M. Corporeal cuts: Surgery and the psycho-social. Body Soc 2008; 14: 31-46.

11. Lakoff $\mathrm{G}$ and Johnson M. Metaphors we live by. Chicago: The University of Chicago Press, 2003.

12. Inspector Y, Kutz I, and David D. Another person's heart: Magical and rational thinking in the psychological adaptation to heart transplantation. Isr J Psychiatry Relat Sci 2004; 41:161-173.

13. Quintin J. Organ transplantation and meaning of life: The quest for self fulfilment. Med Health Care Philos 2013; 16: 565-574.

14. Morse JM. Expanding the application of qualitative findings. Qual Health Res 2008; 18: 1459-1460.

15. Merleau Ponty M. Phenomenology of perception. New York: Routledge, 2014.

16. Levinas E. Otherwise than being or beyond essence. New York: Springer Science+Business Media LLC, 2010.

17. Field PA and Morse JM. Nursing research: The application of qualitative approaches. London: Croom Helm, 1985.

18. Sanner M. Transplant recipients' conceptions of three key phenomena in transplantation: The organ donation, the organ donor, and the organ recipient. Clin Transplant 2003; 17: 391-400.

19. Palmar-Santos AM, Pedraz-Marcos A, Solís-Muñoz M, et al. Theoretical sampling in a phenomenological study regarding the corporeity notion in patients with a heart transplant. Metas Enferm 2011; 14: 68-74.

20. Lincoln YS and Guba EG. Naturalistic inquiry. Newbury Park, USA: Sage Publications, 1985.

21. Tong A and Dew MA. Qualitative research in transplantation: Ensuring relevance and rigor. Transplantation 2016; 100: 710-712

22. Colaizzi P. Psychological research as the phenomenologist view it. In: Valle RS and King M (eds) Essential phenomenological alternatives for psychology. New York: Oxford University Press, 1978, pp.48-71.

23. De Santis L and Ugarriza DN. The concept of theme as used in qualitative nursing research. West J Nurs Res 2000; 22: 351-372.

24. McCormack D. Transplant temporalities and deadly reproductive futurity in Alejandro González Iñárritu's 21 Grams. Eur J Cultural Stud 2016; 19: 51-68.

25. Goetzmann L. Is it me, or isn't it? Transplanted organs and their donors as transitional objects. Am J Psychoanal 2004; 64: 279-289.

26. Winnicott DW. Transitional objects and transitional phenomena. Int J Psychoanal 1953; 34: 89-97.

27. Mauss M. The gift: The form and reason for exchange in archaic societies. New York: WW Norton, 1990.

28. Gill $\mathrm{P}$ and Lowes L. Gift exchange and organ donation: Donor and recipient experiences of live related kidney transplantation. Int J Nurs Stud 2008; 45: 1607-1617.

29. Shildrick M, McKeever P, Abbey S, et al. Troubling dimensions of heart transplantation. Med Humanit 2009; 35: 35.

30. Giddens A. Modernity and self-identity. Self and society in the Late Modern Age. Palo Alto, USA: Stanford University Press, 1991.

31. Monemian S, Abedi $\mathrm{H}$ and Naji SA. Life experiences in heart transplant recipients. J Educ Health Promot 2015; 4: 18. 
32. Peyrovi H, Raiesdana $\mathrm{N}$ and Mehrdad N. Living with a heart transplant: A phenomenological study. Progr Transplant 2014; 24: 234-241.

33. Shildrick M, Carnie A, Wright A, et al. Messy entanglements: Research assemblages in heart transplantation discourses and practices. Med Humanit 2018; 44: 46-54.

34. Ryan M and Farrelly M. Living with an unfixable heart: A qualitative study exploring the experience of living with advanced heart failure. Eur $J$ Cardiovasc Nurs 2009; 8: 223-231.

35. Imes CC, Dougherty CM, Pyper G, et al. Descriptive study of partners' experiences of living with severe heart failure. Heart Lung 2011; 40: 208-216.
36. Janelle C, O'Connor K and Dupuis G. Evaluating illness representations in heart transplant patients. J Health Psychol 2015; 21: 1850-1859.

37. O'Brien GM, Donaghue N, Walker I, et al. Deservingness and gratitude in the context of heart transplantation. Qual Health Res 2014; 24: 1635-1647.

38. Shaw RM and Webb R. Multiple meanings of gift and its value for organ donation. Qual Health Res 2015; 25: 600-611.

39. Aeschylus. Prometheus bound. 26th ed. Mineola, USA: Dover Publications, 1996.

40. Waldron R, Malpus Z, Shearing V, et al. Illness, normality and identity: The experience of heart transplant as a young adult. Disabil Rehabil 2017; 39: 1976-1982. 